\title{
El papel de enfermería en la consulta de enfermedad renal crónica avanzada
}

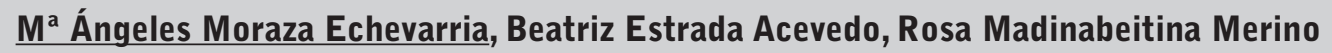

Hospital Universitario de Álava. Txagorritxu. Álava

\section{Introducción:}

La Consulta ERCA está recomendada por el ministerio de Sanidad y las Sociedades Científicas, trata a los pacientes con ERC estadio 4 y 5 y tiene que ser multidisciplinar. El papel de la enfermería de nefrología en esta consulta es muy importante ya que nos encargamos de dar información sobre diálisis, dar consejos dietéticos, cuidar el acceso vascular y administrar Fe intravenoso (i.v.) en lo que más que una consulta normal sería considerado el "hospital de día de nefrología". El objetivo de este estudio es analizar la evolución de los pacientes que han estado en nuestra consulta ERCA.

\section{Pacientes y Métodos:}

Papel de enfermería: la información de las técnicas de diálisis y trasplante renal de vivo la basamos en estrategia ascendente, comenzando con información somera oral y escrita, siguiendo con vídeos y finalizando con una visita a las unidades. Respecto a la dieta entregamos información propia y disponemos de libros y herramientas informáticas para ayudarnos en la elaboración de dietas de acuerdo con los gustos del paciente. Cuidamos el acceso vascular desde que se hace y administramos el Fe i.v. ajustando las citas a nuestro ritmo de consultas. Desde 2006 registramos la actividad de nuestra consulta en una base de datos. Cuando empezamos a registrar introdujimos todos los pacientes prevalentes que estaban en esa época en la consulta y después a todos los pacientes incidentes que han pasado por nuestra consulta de insuficiencia renal avanzada. Registramos datos demográficos, causa de insuficiencia renal, elección inicial de los pacientes y destino final.

\section{Resultados:}

Desde 2006 hasta ahora (01/abr/13) hemos registrado a 223 pacientes en nuestra base de datos. De ellos, el $72,6 \%$ eran hombres $(n=162)$ y el $27,4 \%$ mujeres $(n=61)$. La edad media al inicio del seguimiento en la consulta era $62,9 \pm 16,8$ años (intervalo $17-91$ ). La elección de los pacientes que ya han concluido el seguimiento en ERCA fue HD en 55 pacientes, DP en 56, Trasplante en 3, Conservador en 13. El destino final de los pacientes fue, hemodiálisis en 53 pacientes, diálisis peritoneal en 62, trasplante en 2, éxitus en 30, traslado 0 cambio de consulta en 17. Siguen ahora en consulta 59 pacientes. Respecto a los pacientes fallecidos, 5 fueron por neoplasia, 5 muertes súbitas, dos en contexto de demencia, 10 de causa no registrada, 3 en el contexto de uremia, 2 de causa infecciosa, una por isquemia intestinal, otra por arritmia e ICC y otra por OCFA e Insuficiencia respiratoria. El tiempo de seguimiento en la consulta ha sido muy variable, la media es de $620 \pm 666$ días (8-3525). La mediana ha sido de 386 días (IQ: 189-791).

\section{Conclusiones:}

La información dada por la enfermera de nefrología de la consulta ERCA permite una distribución más equitativa en la elección de la técnica de diálisis.

\section{Referencias Bibliográficas}

1. Fernández $S$, Conde N, Cáceres $A$, Ochando A. La alimentación en la enfermedad renal crónica. Madrid; Aula Médica 2009. Edita: ALCER. Patrocina: 
Shire. Colaboran: SEN, SEDEN. Modalidades de tratamiento. http://www.insuficienciarenalcronica. com Nuevas Herramientas de Ayuda a la toma de decisión compartida del tratamiento sustitutivo renal. Avalado por: ONT, ALCER, SEDEN, SEN.
Federación Andaluza, Sociedad Andaluza de Nefrología. ADER, ERTE. Programa ELECCIÓN (CD vídeo): Herramienta educativa para la elección del tratamiento sustitutivo de la función renal. AMGEN. Avalado por: SEN, SEDEN, ALCER, SET. 